\title{
Adverse Effect of Aerosol Pesticide on Lung Dysfunction among Paddy Farmers in Purworejo, Central Java, Indonesia
}

\author{
Fajaria Nurcandra ${ }^{*}$, Renti Mahkota ${ }^{2,3}$, Tri Y M Wahyono ${ }^{3}$
}

${ }^{1}$ Public Health, Faculty of Health Science, Universitas Pembangunan Veteran Jakarta, Indonesia

2Doctoral Student, Department of Epidemiology, Faculty of Public Health, Mahidol University, Thailand

${ }^{3}$ Department of Epidemiology, Faculty of Public Health, Universitas Indonesia, Indonesia

\begin{abstract}
The World Health Organization estimated that chronic obstructive pulmonary disease (COPD) will be the highest non-communicable disease worldwide by 2030 , and pesticide exposure is one of major risk factors. This study aimed to determine effect of pesticide exposure on lung dysfunction among paddy farmers. A case-control study was performed on April - May 2016 in Purworejo. The case group comprised 66 farmers suffering from lung dysfunction during 2015 based on medical records, while the control group comprised 59 neighboring farmers showing normal lung function. Both case and control groups were tested using a spirometer and COPD assessment test (CAT) questionnaire. Logistic regression analysis of pesticide quantity $(\mathrm{OR}=0.75 ; 95 \% \mathrm{Cl}=0.317$ 1.754) and duration of spraying $(\mathrm{OR}=1.11 ; 95 \% \mathrm{Cl}=0.430-2.891)$ adjusted for confounders showed no clear associations. Pesticide remained a potential health risk for lung dysfunction due to farming duration $(\mathrm{OR}=5.61 ; 95 \% \mathrm{Cl}=1.124-27.990)$ adjusted by age, personal protective equipment, records of lung disease, smoking habit, dust exposure, and indoor air pollution. The farming duration was revealed to be a risk factor, but no clear association was found between quantity and duration of spraying to lung dysfunction.
\end{abstract}

Keywords: aerosol, chronic obstructive pulmonary disease, farmer, lung dysfunction, pesticide

\section{Introduction}

Global Initiative for Chronic Obstructive Lung Disease defined chronic obstructive pulmonary disease (COPD) as progressive lung disease where airways in the lungs are damaged. ${ }^{1}$ Symptoms related to several respiratory problems have been reported in agricultural workers, and these symptoms may be a systemic effect on the lungs after pesticide inhalation. Occupational exposure, especially pesticide exposure, has been associated with respiratory symptoms and chronic respiratory disease. ${ }^{2-5}$ COPD lung dysfunction is expected to become the third leading cause of death by 2030.6

More than 1.1 billion workers worldwide work in the agricultural sector (about 34\% of the global working force). This large number may affect adverse health associated with occupational exposure to pesticides, which can have a large public health impact. 6 The exposed population to pesticides is higher in developing countries than in developed countries due to the climate, poor personal protective equipment (PPE) usage, and lack of safety training. Exposure to organic dust, pesticides, and hazardous agricultural chemicals may cause respiratory dis-

Correspondence $^{*}$ : Fajaria Nurcandra, Public Health Studies, Faculty of Health Science, Universitas Pembangunan Nasional Veteran Jakarta, RS Fatmawati Street, Pondok Labu, South Jakarta, Jakarta, Indonesia, E-mail: fnurcandra@gmail.com, Phone: +62-89654211643 eases and decline in lung function. 7,8

Occupational exposure of dust, smoke, gases, and vapors was reported as a cause of decline in forced expiratory volume in the first second $\left(\mathrm{FEV}_{1}\right)$ and $\mathrm{FEV}_{1} / \mathrm{FVC}$, as well as obstruction of the high prevalence of mild and moderate/severe COPD. ${ }^{7,9,10}$ Given that farmers' pulmonary health functions are rarely monitored, occupational diseases including lung dysfunction may be underreported. Occupational lung dysfunction is characterized by chronic cough, sputum, shortness of breath, shortness of breath, chest tightness, chronic bronchitis, asthma, and COPD. 7,11 Furthermore, Indonesia lacks a medical check-up program for farmers to determine the occupational exposure effect of pesticide on lung function.

On the basis of the reported cases of lung dysfunction in males from 27 primary health care, there were 114 cases and 459 cases in Tjitrowardojo State Hospital. Purworejo is also known as the center of the nation's largest seed and agricultural land, and agriculture is this district's main source of income. Although cigarettes have been widely reported as a cause of lung dysfunction, studies on lung dysfunction caused by exposure to pesti- 
cides among farmers are rare. Unfortunately, our rice farmers in Indonesia use the traditional method of spraying without using PPE, especially protection for the respiratory system, which is a potential risk for lung dysfunction due to long-term exposure. This paper analyzed whether pesticide exposure (e.g., pesticide quantity, spraying duration, and duration of farming) is associated with lung dysfunction among farmers.

\section{Method}

A case - control study was performed on April 14, 2016 to May 2, 2016 in Purworejo District, Central Java, Indonesia. The study population comprised farmers aged at least 40 years. This age was chosen because it is the age at which lung function begins to decline or lung dysfunction (COPD grade 1 / COPD I) begins to occur without symptoms. Samples were selected based on primary health care registers and medical records of Tjitrowardojo State Hospital along 2015.

Purposive sampling and restriction were carried out in males because of the high proportion of male pesticide sprayers. Data on the COPD lung dysfunction group were obtained from medical records in Tjitrowardojo State Hospitals and primary health care, whereas the non-lung dysfunction group was composed of the nearest neighbors working as farmers, with a measuring spirometer showing normal results $\left(\mathrm{FEV}_{1} / \mathrm{FVC}>0.70\right.$ and $\mathrm{FEV}_{1}$ predictive $>80 \%$ ). The lung function of both groups was measured using a spirometer and questionnaire, namely COPD assessment test / CAT. A total of 125 participants were visited in their homes.

A total of 66 cases were visited in their home for an interview; body height, body weight, and lung function were measured. The same measurements were obtained in 59 controls. Data were collected with the assisstance of three enumerators who were trained to interview based on the questionnaire and blinded to hypothesis of this study. The questionnaire was tested for validity and reliability in 25 farmers excluded from this study.

All participants were interviewed about pesticide exposure (quantity in unit/year, duration of spraying, and duration of farming) and respiratory symptoms over the last 12 months. Pesticide quantity was defined as the average volume of pesticides used in units or liters for a year. Categorization was based on previous study to minimize error where the scores of 0 - 9 units/year and $>9$ units/year. ${ }^{7}$ The duration of spraying in this study was determined by the number of years of pesticide use multiplied by the average hours required for spraying. ${ }^{9}$ Potential confounding variables of this study were land area, age, education level, body mass index (BMI), personal hygiene, PPE, lung disease record, having pet, smoking, dust exposure, and indoor air pollution of combution from fuel used for cooking. Clinical symptoms of lung dysfunction were asked using the CAT.

Lung function test was performed using a portable spirometer, and $\mathrm{FEV}_{1} / \mathrm{FVC}$ and $\mathrm{FEV}_{1}$ were measured. For valid results, all participants were allowed to rest for 15 minutes and not allowed to smoke for 1 hour before measurement. The procedure was carefully described to the farmers with emphasis on the need to avoid leaks round the mouthpiece and to make a maximum inspiration with complete expiration without hesitation and without leaning forward. The procedure was demonstrated using a detached mouthpiece with a nose clip in an upright posture, and tight clothing was loosened. ${ }^{7}$ Participants were allowed to practice twice before the actual measurement. Each farmer performed three acceptable forced expiratory maneuvers, and the highest result was obtained.

We used statistical software. All variables were analyzed for frequency distribution. Chi-square test was performed with $\alpha=0.05$, odds ratio (OR), and $95 \%$ confidence interval $(\mathrm{CI})$ to identify statistical confounding variables. Crude associations between pesticide exposure (quantity in unit/year, duration of spraying, and duration of farming) and lung dysfunction were analyzed and adjusted to identify potential confounding and modifier effects. Substantial confounding was expected from smoking, dust, lung disease record, and indoor air pollution. A backward method of logistic regression was conducted to analyze the effect of pesticide exposure on lung dysfunction. If $95 \% \mathrm{CI}$ did not pass the null value, then the null hypothesis was rejected, and the difference was statistically significant.

The Ethics Commissions of Research and Community Engagement, Faculty of Public Health, Universitas Indonesia, approved the study protocol (No. 35/UN2.F10/PPM.00.02/2016). Before the interview, the participants received explanation on the purpose of the study. Written informed consent was obtained from all participants on a voluntary basis.

\section{Results}

Data from the primary health care and Tjitrowardojo State Hospital included COPD exacerbation. A total of 84 patients with COPD were eligible for participation after cleaning; these patients were from the community health center. By contrast, 153 patients with COPD were from Tjitrowardojo State Hospital. Sixty-six of the selected cases have lived in sub-districts with most agricultural areas. A total of 127 questionnaires were collected, but two questionnaires of the case group were excluded due to lung function measurement error. Before being interviewed, two cases and two controls refused to participate in this study, so the nonparticipation rate was $3.10 \%$.

The case group was measured using a spirometer according to $\mathrm{FEV}_{1} / \mathrm{FVC}$ and $\mathrm{FEV}_{1}$. A total of 42 samples 
suffered from COPD II, 15 suffered from COPD III, and 9 had COPD IV, but none suffered from COPD I because patients with medical records presented with mild to severe conditions. In terms of the lung function measurement results of the control group, all samples showed $\mathrm{FEV}_{1} / \mathrm{FVC}>0.70$ and $\mathrm{FEV}_{1}>80 \%$.

Table 1 shows that pesticide exposure based on quantity was higher in the control group than in the case group. The duration of farming $\geq 26$ hours/year was higher in the control group than in the case group. More than half of the farmers had been working as farmers $\geq$ 11 years. The proportion of land area $\geq 2000 \mathrm{~m}^{2}$. COPD in age $\geq 58$ years was found higher than non-lung dysfunction. The body mass index $(\mathrm{BMI}) \geq 20.31$, education level < junior high school, monthly income < IDR 750,000 , lung disease record, smoking behavior, dust exposure, and indoor air pollution were higher in the case group than in the control group. In contrast, bad personal hygiene and bad PPE used were higher in the control group than in the case group. Furthermore, having a risky pet was equal in both the case and control groups.

Pesticide quantity, duration of spraying, and duration of farming were categorized based on a previous study for univariate analysis. However, the categorization was not fit for bivariate analysis of the study, so those variables were re-categorized using the receiver operating characteristic (ROC) value as a cut-off point. Table 2 shows no difference in pesticide quantity $\geq 12$ units/year between both groups, and no significant association was found between pesticide quantity and lung dysfunction in farmers $(\mathrm{OR}=0.53 ; 95 \% \mathrm{CI}=0.24-1.14)$. The ORs showed protective effect in crude association. The CI range passed the null value, which needs to be analyzed further to explain the magnitude of pesticide quantity to

Table 1. Distribution of Characteristics of Paddy Farmers with Chronic Obstructive Pulmonary Disease in Purworejo District, 2016

\begin{tabular}{|c|c|c|c|c|c|c|}
\hline \multirow{2}{*}{ Variable } & \multirow{2}{*}{ Category } & \multicolumn{2}{|c|}{ COPD } & \multirow{2}{*}{ Total } & \multirow{2}{*}{ p-value } & \multirow{2}{*}{ OR $(95 \% \mathrm{CI})$} \\
\hline & & Case & Control & & & \\
\hline \multirow[t]{2}{*}{ Land area } & $\geq 2,000 \mathrm{~m}^{2}$ & $33(50.00 \%)$ & $34(57.63 \%)$ & $67(53.60 \%)$ & 0.393 & $0,73(0.34-1.58)$ \\
\hline & $<2,000 \mathrm{~m}^{2}$ & $33(50.00 \%)$ & $25(42.37 \%)$ & $58(46.40 \%)$ & & \\
\hline \multirow[t]{2}{*}{ Age } & $\geq 58$ years & $36(54.55 \%)$ & $29(49.15 \%)$ & $65(52.00 \%)$ & 0.547 & $1,24(0.58-2.66)$ \\
\hline & $<58$ years & $30(45.45 \%)$ & $30(50.85 \%)$ & $60(48.00 \%)$ & & \\
\hline \multirow[t]{2}{*}{ Body mass index } & $\geq 20.31$ & $27(40.91 \%)$ & $39(66.10 \%)$ & $66(52.80 \%)$ & 0,005 & $2.82(1.28-6.24)$ \\
\hline & $<20.31$ & $39(59.09 \%)$ & $20(33.90 \%)$ & $59(47.20 \%)$ & & \\
\hline \multirow[t]{2}{*}{ Education level } & $<$ Junior high school & $43(65,15 \%)$ & $32(54.24 \%)$ & $75(60.00 \%)$ & 0.214 & $1.58(0.72-3.45)$ \\
\hline & $\geq$ Junior high school & $23(34,85 \%)$ & $27(45.76 \%)$ & $50(40.00 \%)$ & & \\
\hline \multirow[t]{2}{*}{ Monthly income (IDR) } & $<750,000$ & $42(63,64 \%)$ & $26(44.07 \%)$ & $68(54.40 \%)$ & 0.028 & $2.22(1.02-4.85)$ \\
\hline & $\geq 750,000$ & $24(36,36 \%)$ & $33(55.93 \%)$ & $57(45.60 \%)$ & & \\
\hline \multirow[t]{2}{*}{ Personal hygiene } & Poor & $24(36,36 \%)$ & $24(40.68 \%)$ & $48(38.40 \%)$ & 0.620 & $0.83(0.38-1.83)$ \\
\hline & Good & $42(63,64 \%)$ & $35(59.32 \%)$ & $77(61.60 \%)$ & & \\
\hline \multirow[t]{2}{*}{ PPE used } & Poor & $48(72,73 \%)$ & $52(88.14 \%)$ & $100(80.00 \%)$ & 0.032 & $0.36(0.12-1.01)$ \\
\hline & Good & $18(27,27 \%)$ & $7(11.86 \%)$ & $25(20.00 \%)$ & & \\
\hline \multirow[t]{2}{*}{ Lung disease records } & Yes & $26(39.39 \%)$ & $7(11.86 \%)$ & $33(26.40 \%)$ & 0.000 & $4.83(1.79-14.38)$ \\
\hline & No & $40(60.61 \%)$ & $52(88.14 \%)$ & $92(73.60 \%)$ & & \\
\hline \multirow[t]{2}{*}{ Pet } & Risk & $11(16.67 \%)$ & $10(16.95 \%)$ & $21(16.80 \%)$ & 0.966 & $0.98(0.34-2.82)$ \\
\hline & No risk & $55(83.33 \%)$ & $49(83.05 \%)$ & $104(83.20 \%)$ & & \\
\hline \multirow[t]{2}{*}{ Smoking behaviors } & High & $10(15.15 \%)$ & $7(11.86 \%)$ & $17(13.60 \%)$ & 0.592 & $1.33(0.42-4.42$ \\
\hline & Low-middle & $56(84.85 \%)$ & $52(88.14 \%)$ & $108(86.40 \%)$ & & \\
\hline \multirow[t]{2}{*}{ Dust exposure } & Yes & $39(59.09 \%)$ & $29(49.15 \%)$ & $68(54.40 \%)$ & 0.265 & $1.49(0.69-3.22)$ \\
\hline & No & $27(40.91 \%)$ & $30(50.85 \%)$ & $57(45.60 \%)$ & & \\
\hline \multirow[t]{2}{*}{ Indoor air pollution } & Yes & $60(90.91 \%)$ & $51(56.44 \%)$ & $111(88.80 \%)$ & 0.429 & $1.57(0.44-5.85)$ \\
\hline & No & $6(9.09 \%)$ & $8(13.56 \%)$ & $14(11.20 \%)$ & & \\
\hline
\end{tabular}

Notes: PPE: Personal Protective Equipment; COPD: Chronic Obstructive Pulmonary Disease; CI: Confidence Interval; OR: Odd Ratio

Table 2. Association between Pesticide Exposure and Chronic Obstructive Pulmonary Disease among Farmer in Purworejo District, 2016

\begin{tabular}{|c|c|c|c|c|c|c|}
\hline \multirow{2}{*}{ Variable } & \multirow{2}{*}{ Category } & \multicolumn{2}{|c|}{ COPD } & \multirow{2}{*}{ Total } & \multirow{2}{*}{ p-value } & \multirow{2}{*}{ OR $(95 \%$ CI $)$} \\
\hline & & Case & Control & & & \\
\hline \multirow[t]{2}{*}{ Pesticide quantity } & $\geq 12$ units/year & $31(46.97 \%)$ & $37(62.71 \%)$ & $57(45.60 \%)$ & 0.077 & $0.53(0.24-1.14)$ \\
\hline & $<12$ units/year & $35(53.03 \%)$ & $22(37.29 \%)$ & $68(54.40 \%)$ & & \\
\hline \multirow[t]{2}{*}{ Duration of spraying } & $\geq 26$ hours/year & $28(42.42 \%)$ & $33(55.93 \%)$ & $64(51.20 \%)$ & 0.131 & $0.58(0.27-1.25)$ \\
\hline & $<26$ hours/year & $38(57.58 \%)$ & $26(44.07 \%)$ & $61(48.40 \%)$ & & \\
\hline \multirow[t]{2}{*}{ Duration of farming } & $\geq 11$ years & $63(95.45 \%)$ & $50(84.75 \%)$ & $113(90.40)$ & 0.042 & $3.78(0.87-22.61)$ \\
\hline & $<11$ years & $3(4.55 \%)$ & $9(15.25 \%)$ & $12(9.60 \%)$ & & \\
\hline
\end{tabular}

Notes: COPD: Chronic Obstructive Pulmonary Disease; CI: Confidence Interval; OR: Odd Ratio 
Table 3. Adjusted Risk of Pesticide Effect to Chronic Obstructive Pulmonary Disease in Farmers

\begin{tabular}{|c|c|c|c|c|c|c|}
\hline \multirow{2}{*}{ Variable } & \multirow{2}{*}{ OR } & \multirow{2}{*}{ SE } & \multirow{2}{*}{ Z-score } & \multirow{2}{*}{ p-value } & \multicolumn{2}{|c|}{$\mathbf{9 5} \% \mathbf{C I}$} \\
\hline & & & & & Lower & Upper \\
\hline Pesticide quantity $\geq 12$ units/year & 0.75 & 0.325 & -0.67 & 0.502 & 0.317 & 1.754 \\
\hline Duration of spraying $\geq 26$ hours/year & 5.10 & 3.771 & 2.20 & 0.028 & 1.195 & 21.731 \\
\hline Monthly income < IDR 750,000 & 2.06 & 0.790 & 1.89 & 0.059 & 0.972 & 4.369 \\
\hline Bad PPE used & 0.36 & 0.218 & -1.69 & 0.091 & 0.110 & 1.176 \\
\hline High BI of smoking behavior & 0.85 & 0.489 & -0.28 & 0.779 & 0.276 & 2.624 \\
\hline
\end{tabular}

Notes: OR: Odd Ratio; SE: Standard Error; CI: Confidence Interval; PPE: Personal Protective Equipment; BI: Brinkman Index

Table 4. Adjusted Risk of Duration of Spraying to Chronic Obstructive Pulmonary Disease

\begin{tabular}{|c|c|c|c|c|c|c|}
\hline \multirow{2}{*}{ Variable } & \multirow{2}{*}{ OR } & \multirow{2}{*}{ SE } & \multirow{2}{*}{ Z-score } & \multirow{2}{*}{ p-value } & \multicolumn{2}{|c|}{ 95\% CI } \\
\hline & & & & & Lower & Upper \\
\hline Duration of spraying $\geq 26$ hours/year & 1.11 & 0.542 & 0.22 & 0.822 & 0.430 & 2.891 \\
\hline Pesticide quantity $\geq 12$ units/year & 0.60 & 0.280 & -1.09 & 0.276 & 0.242 & 1.499 \\
\hline Duration of farming $\geq 11$ years & 5.44 & 4.329 & 2.13 & 0.033 & 1.144 & 25.879 \\
\hline Age $\geq 58$ years & 0.72 & 0.305 & -0.78 & 0.436 & 0.312 & 1.652 \\
\hline Bad PPE used & 0.38 & 0.255 & -1.44 & 0.149 & 0.101 & 1.414 \\
\hline Had lung disease record & 5.50 & 2.941 & 3.18 & 0.001 & 1.925 & 15.688 \\
\hline High BI of smoking behavior & 0.76 & 0.477 & -0.44 & 0.662 & 0.222 & 2.600 \\
\hline
\end{tabular}

Notes: OR: Odd Ratio; SE: Standard Error; CI: Confidence Interval; PPE: Personal Protective Equipment; BI: Brinkman Index

indicate lung dysfunction. In addition, the risk magnitude must be reviewed because the risk will increase when more pesticide quantity is used. The land area was found to be an effect modifier, and PPE used was a confounder to the relationship between pesticide quantity and lung dysfunction in stratification analysis.

The proportion of duration of spraying was higher in the control group for the $\geq 26$ hours/years than that in the case group. However, we found no significant relationship between pesticide used based on the duration with lung physiology abnormalities in farmers $(\mathrm{OR}=$ $0.58 ; 95 \% \mathrm{CI}=0.27-1.25)$, thereby indicating protective effect (Table 2). However, the CI range passed the null value, which should be analyzed further to determine the extent of risk on the basis of the duration of the exposure. PPE used and lung disease history were found as potential confounders based on stratified analysis.

The chi-square test obtained p-value of 0.042, which indicated a significant relation between the usage of pesticide based on the farming duration and lung dysfunction in farmers $(\mathrm{OR}=3.78$; 95\% CI $=0.87-22.61)$. Thus, farmers with duration of spraying $\geq 11$ hours/year were 3.78 times higher to suffer from lung dysfunction than farmers with duration of spraying $<11$ hours/year (Table 2). However, the CI range passed the null value, which should be analyzed further to examine the risk magnitude due to the duration of pesticide exposure. Education level and having a pet were found to be effect modifiers in stratified analysis. Education level, PPE used, and history of lung disease were considered potential confounders based on stratified analysis.

Logistic regression showed that pesticide quantity had a $\mathrm{p}$-value $>0.05(\mathrm{OR}=0.75 ; 95 \% \mathrm{CI}=0.317-1.754)$ after controlled by PPE used, monthly income, duration of farming, and duration of smoking behavior (Table 3). The adjusted risk of duration of spraying had a p-value $>$ $0.05(\mathrm{OR}=1.11 ; 95 \% \mathrm{CI}=0.430-2.891)$ controlled by PPE used, smoking behavior, age, pesticide quantity, record of lung disease, and duration of farming (Table 4). However, those results showed no clear association. The farming duration was a significant risk factor for lung dysfunction ( $\mathrm{p}$-value $<0.05$; OR $=5.61 ; 95 \% \mathrm{CI}=1.124$ - 27.990) after controlled by age, PPE used, lung disease record, smoking behavior, dust exposure, and indoor air pollution (Table 5). Farmers with a duration of farming $\geq 11$ years were 5.61 fold likely to suffer from lung dysfunction than those with a duration of farming $<11$ years.

\section{Discussion}

Most subjects ignored the symptoms of lung dysfunction as symptoms of usual respiratory disease. Farmers also believed that the decline in lung function was a normal disease of the elderly. These symptoms may be silent at the prodromal stage due to compensatory reactions. An important lung function test was performed as an objective assessment, early diagnosis, determination of the location of the lesion, and identification of reasons for shortness of breath. ${ }^{11}$ 
Table 5. Adjusted Risk of Duration of Farming to Chronic Obstructive Pulmonary Disease

\begin{tabular}{llrrrrr}
\hline Variable & OR & SE & Z-score & p-value & \multicolumn{2}{c}{ 95\% CI } \\
\cline { 3 - 6 } & & & & Lower & Upper \\
\hline Duration of farming $\geq 11$ years & 5.61 & 4.600 & 2.10 & 0.036 & 1.124 & 27.990 \\
Age $\geq 58$ years & 0.75 & 0.321 & -0.67 & 0.503 & 0.325 & 1.736 \\
Bad PPE used & 0.33 & 0.184 & -1.99 & 0.047 & 0.110 & 0.984 \\
Had lung disease record & 5.29 & 2.736 & 3.22 & 0.001 & 1.921 & 14.578 \\
High BI of smoking behavior & 0.81 & 0.504 & -0.34 & 0.736 & 0.240 & 2.740 \\
Dust exposure & 1.60 & 0.694 & 1.08 & 0.279 & 0.683 & 3.744 \\
Indoor air pollution & 0.60 & 0.694 & -0.00 & 0.997 & 0.255 & 3.904 \\
\hline
\end{tabular}

Notes: OR: Odd Ratio; SE: Standard Error; CI: Confidence Interval; PPE: Personal Protective Equipment; BI: Brinkman Index

The relationship among pesticide quantities, duration of spraying, and duration of farming were most influenced by bad PPE used and high Brinkman index of smoking behavior. This study showed that most male farmers were smokers, which confirmed that cigarette was a direct factor of lung dysfunction. ${ }^{11}$ Poor use of PPE among farmers was reported in a previous study. The farmers reported feeling uncomfortable in using PPE during handling and spraying pesticide in hot weather. ${ }^{4}$ The effect of pesticides on lung dysfunction may be due to previous lung disease (low-grade asthma or COPD). Repeated exposure to pesticides may also increase the risk for healthy individuals to suffer from respiratory decline. In accordance with the conditions in this study, one of the confounding factors that affected the magnitude risk of pesticide exposure to lung dysfunction is a record of lung disease. ${ }^{12}$

Neither this study nor previous studies found an association between pesticide quantity and lung dysfunction. Consistency in these two studies was probably due to the temporal ambiguity in which a person diagnosed with an illness or was feeling sick would tend to reduce or eliminate exposure. ${ }^{7}$ Respondents who suffered from lung dysfunction experience a decrease in body stamina, so that they could no longer afford to spray pesticides or will reduce spraying duration/frequency activity. The CI range indicated that the upper limit was a risk factor, whereas the lower limit showed a protective effect after a person was diagnosed with lung dysfunction because of exposure elimination. In addition, the lack of a clear association was probably due to strict restriction and regulation of pesticides in the market. ${ }^{6}$ However, active ingredients of pesticides most used in this study subjects are methomyl, alphamethrin, deltamethrin, and diazinon. Those are easily to get in the local market.

In contrast, a cohort study in the Netherlands with Lifelines data reported that vapor, gas, dust, and fume exposure is associated with $\mathrm{FEV}_{1}$ and $\mathrm{FEV}_{1} / \mathrm{FVC}$ and the prevalence of intermediate to severe respiratory tract obstruction. The risk of exposure to pesticides was 1.08 $(95 \% \mathrm{CI}=0.61-1.90)$ times greater for moderate pesti- cide exposure and 1.78 times $(95 \% \mathrm{CI}=1.14-2.79)$ greater than those with low pesticide exposure. ${ }^{9}$ Other studies suggested that organophosphate exposure in the workplace causes respiratory disease and pulmonary function decline in pesticide spraying workers in North India's mango gardens. ${ }^{7}$ There may be different effects of organophosphate pesticide use on lung dysfunction in farmers, but these effects were not examined in this study. The present study only estimated the effect of respirable pesticide fumes, which were found to influence lung dysfunction for long-term exposure. A previous study among pesticide sprayers also found a significant decline in lung function and acetyl-cholinesterase levels after exposure to pesticides during spraying. ${ }^{13}$

On the basis of the dose-response relationship, a large land area will need a large pesticide volume. Wide rice fields will need additional pesticides. The weak dose-response relationship in this study may be due to economic factors. If a person has a large rice field, then that person is an upper-middle economic class who can pay or have someone else to spray his rice field. Therefore, upper economic farmers are less likely to be exposed to pesticides than farmers from other classes. This lack of linkage is also probably caused by local farmers' awareness of harmful pesticides and the present study design. ${ }^{8}$ This phenomenon probably happened to the respondents of this study as no significant association was found between pesticide quantity and lung dysfunction.

Effects of pesticides depend on the degree of toxicity, dosage, absorption rate on the body, temperature, and duration of pesticide use. ${ }^{4}$ If farmers are aware of the harmfulness of pesticides to their health, then they will use complete PPE for a large volume of pesticides. Proper PPE used during preparation and spraying of pesticides is supported by good behavior of personal hygiene, and wind direction during spraying can decrease the risk of pesticide exposure. ${ }^{3}$ These results are supported by the findings of a previous analysis, which showed that PPE use can reduce the risk of exposure. These results were similar to the conditions of Brazilian farmers and those in this study who frequently handle multiple pesticides 
and apply them using manual pumping or backpack tanks. ${ }^{9}$ While, the study only assessed pesticide exposure on the basis of direct contact during preparation and spraying.

The probability of selection bias in this study was very low because the control group was selected from an actual base population where the case group was from. The case and control groups were treated, and the same measurements were carried out. To avoid the Clever Hans Effect, some pesticide exposure questions and related variables confirmed the truth of the family.

Health effects of pesticide exposure depend on the duration/frequency, pesticide concentration, and PPE used. ${ }^{10}$ The risk magnitude of duration of praying in this study was weak $(\mathrm{OR}=1.11 ; 95 \% \mathrm{CI}=0.430-2.891)$ after controlled by PPE used, smoking behavior, age, pesticide quantity, lung disease record, and duration of farming. The dose-response relationship of pesticide exposure level based on duration was reported in previous studies and consistent with the results in this study. The amount of risk based on spraying duration increased by 1 point for the duration of work $11-50,51-100$, and $\geq 101.4,5$ These findings were probably due to the behavior of pesticide applicators who wore incomplete PPE during highlevel pesticide exposure. ${ }^{14,15}$

Cumulative exposure classification of previous studies showed a significant increase in chronic bronchitis in the presence of increased intensity / duration of pesticide exposure. ${ }^{9}$ Crude risk of previous study on mango farmers found that the crude risk increases depending on the increased duration of work. Farmers with a duration of work $>11$ years were at 1.62 times greater risk than those with a duration of work $<11$ years. Duration of spraying and stirring of pesticides was reported as a predictor of respiratory and respiratory tract irritation. ${ }^{7}$

The duration of farming in this study was defined as the length of time respondents work as farmers as the main job. Strong risk magnitude $(\mathrm{OR}=5.61 ; 95 \% \mathrm{CI}=$ 1.124 - 27.990) was observed after controlling smoke exposure, smoking behavior, age, dust exposure, PPE used, and lung disease record. This OR indicated a very strong relationship between duration of farming and lung dysfunction. A dose-response relationship based on duration of farming and plausibility in accordance with the amount of risk was obtained statistically. The longer a person works as a farmer, the probability of use and exposure to pesticides increases and the risk of lung dysfunction rises as well. The range of cumulative interval may be due to unmeasured variables or non-differential misclassification. The magnitude of duration of farming is consistent with the decline in lung function in crude factor by duration of farming $>20$ years, spraying pesticides, and dust exposure. ${ }^{9}$ Studies in Florida among pest control workers exposed to long-term organophosphates, carbamates, and phenyoxyacetic acid revealed a high mortality rate of lung cancer $(\mathrm{OR}=1.4 ; 95 \% \mathrm{CI}=0.7$ 3.0 for subjects exposed for $10-19$ years, $\mathrm{OR}=2.1$; $95 \% \mathrm{CI}=0.8-5.5$ for subjects working for $>20$ years). ${ }^{16}$

The duration of farming was found to be an important factor that affects the increased prevalence of lung function decline. Farmers with a longer working period were reported to be at significantly higher risk to have symptoms than those with shorter working period. ${ }^{5}$ On the basis of data from the US Sentinel Event Notification System for Occupational Risks, a surveillance of pesticide effects, the total incidence rate due to acute pesticide exposure of 1.17 per 100,000 and insecticides contributed top $49 \%$ of total incidents. ${ }^{5}$ Lung function decline due to long-term exposure to pesticides may be affected by other factors such as poor PPE because of poor socio-economic conditions. ${ }^{13}$ However, studies in the Netherlands based on longitudinal data from The European Community Respiratory Health Survey did not show any effect from active pesticide composition, pesticide application methods, and PPE as protective factors. ${ }^{15}$ A systematic review reported four cross-sectional studies of 41 studies that found obstruction or restrictions of respiratory function related to pesticide exposure according to the chemical class of pesticides. Other cohort studies found a significant association with increased risk of wheezing, asthma, and chronic bronchitis. ${ }^{17}$ Time variable related to long-term pesticide exposure of those studies probably caused the abovementioned respiratory diseases.

In this study, bias introduced using non-differential misclassification possibly underestimated the results of risk magnitude because the same measurements were made for the case and control groups. Temporal ambiguity may exist in the crude OR, but not in the adjusted OR.

\section{Conclusion}

The study found no clear association between lung dysfunction and average pesticide quantity and duration of spraying during the farming period. The farming duration was a strong risk factor for lung dysfunction. Further study may include non-smokers group to distinguish the effect of pesticide on lung dysfunction between smokers and non-smokers.

\footnotetext{
Abbreviations

CAT: COPD Assessment Test; COPD: Chronic Obstructive Pulmonary Disease; PPE: Personal Protective Equipment; $\mathrm{FEV}_{1}$ : Forced Expiratory Volume in the first second; FVC: Forced Vital Capacity; BMI: Body Mass Index; OR: Odds Ratio; CI: Confidence Intervals; BI: Brinkman Index; ROC: Receiver Operating Characteristic.
} 


\section{Ethics Approval and Consent to Participate}

The Ethics Commissions of Research and Community Engagement, Faculty of Public Health, Universitas Indonesia, approved the study protocol (No. 35/UN2.F10/PPM.00.02/2016). Written informed consent was obtained from all participants on a voluntary basis.

\section{Competing Interest}

Author declares that there are no significant competing financial, professional, or personal interests that might have affected the performance or presentation of the work described in this manuscript.

\section{Availability of Data and Materials}

The datasets used and/or analyzed during the current study are available from the corresponding author on reasonable request.

\section{Authors' Contribution}

Fajaria Nurcandra, Renti Mahkota, Tri Y M Wahyono are involved in conceptualizing and designing the study. Fajaria Nurcandra searched the literature and prepared the questionnaire and collected the data. Fajaria Nurcandra and Renti Mahkota analyzed the data and prepared the manuscript. All authors reviewed the manuscript and approved the final manuscript.

\section{Acknowledgment}

The authors would like to thank the Ministry of Education and Culture for Beasiswa Unggulan Pegiat Sosial-Seniman (Excellent Social Activist and Artist Scholarship), which fully funded this research, and Dr. Feni Fitriani, Sp.P, M.Pd.Ked for the preparation of this study.

\section{References}

1. Perret JL, Walters EH, Abramson MJ, Mcdonald CF, Dharmage SC. The independent and combined effects of lifetime smoke exposures and asthma as they relate to COPD. Expert Review of Respiratory Medicine. 2014; 8 (4): 503-14.

2. Rinsky JL. The role of occupational exposure to animal production in chronic obstructive pulmonary disease among farmers in Iowa and North Carolina. University of North Carolina; 2015.

3. Buralli RJ, Ribeiro H, Mauad T, Amato-Lourenço LF, Salge JM, DiazQuijano FA, et al. Respiratory condition of family farmers exposed to pesticides in the State of Rio de Janeiro, Brazil. International Journal of Environmental Research and Public Health. 2018; 15(6).

4. Nurcandra F, Mahkota R, Shivalli S. Effect of personal protective equipment during pesticide application to neurological symptoms in farmers in Purworejo District, Indonesia. Kesmas: National Public Health Journal. 2018; 12(4): 165-71.

5. Ye M, Beach J, Martin JW, Senthilselvan A. Occupational pesticide exposures and respiratory health. International Journal of Environmental Research and Public Health. 2013; 10 (12): 6442-71.
6. de Jong K, Boezen H, Kromhout H, Vermeulen R, Postma D, Vonk J. Pesticides and other occupational exposures are associated with airway obstruction: the LifeLines cohort study. Journal of Occupational and Environmental Medicine. 2014; 71 (2): 88-96.

7. Abu Sham'a F, Skogstad M, Nijem K, Bjertness E, Kristensen P. Lung function and respiratory symptoms in male Palestinian farmers. Archives of Environmental \& Occupational Health. 2010; 65 (4): 191-200.

8. Damalas CA, Eleftherohorinos IG. Pesticide exposure, safety issues, and risk assessment indicators. International Journal of Environmental Research and Public Health. 2011; 8 (5): 1402-19.

9. Fareed M, Pathak MK, Bihari V, Kamal R, Srivastava AK, Kesavachandran $\mathrm{CN}$. Adverse respiratory health and hematological alterations among agricultural workers occupationally exposed to organophosphate pesticides: a cross-sectional study in North India. PLoS One. 2013; 8 (7): e69755.

10. Sapbamrer R, Nata S. Health symptoms related to pesticide exposure and agricultural tasks among rice farmers from Northern Thailand. Environmental Health and Preventive Medicine. 2014; 19 (1): 12-20.

11. Zhu X, Gao P, Gu Y, Xiao P, Liu M, Chen J, et al. Positive rates and factors associated with abnormal lung function of greenhouse workers in China: a cross-sectional study. International Journal of Environmental Research and Public Health. 2017; 14 (9): 956.

12. Doust E, Ayres JG, Devereux G, Dick F, Crawford JO, Cowie H, et al. Is pesticide exposure a cause of obstructive airways disease?. The European Respiratory Review. 2014; 23 (132): 180-92.

13. Pathak MK, Fareed M, Srivastava AK, Pangtey BS, Bihari V, Kuddus $\mathrm{M}$, et al. Seasonal variations in cholinesterase activity, nerve conduction velocity and lung function among sprayers exposed to mixture of pesticides. Environmental Science and Pollution Research. 2013; 20 (10): 7296-300.

14. Alif SM, Dharmage SC, Benke G, Dennekamp M, Burgess JA, Perret JL, et al. Occupational exposure to pesticides are associated with fixed airflow obstruction in middle-age. Thorax. 2017; 72 (11): 990-7.

15. Lytras T, Kogevinas M, Kromhout H, Carsin A, Antó JM, Bentouhami $\mathrm{H}$, et al. Occupational exposures and 20-year incidence of COPD: the European community respiratory health survey. Thorax. 2018; 73 (11): 1008-15.

16. Mohammadien H a., Hussein MT, El-Sokkary RT. Effects of exposure to flour dust on respiratory symptoms and pulmonary function of mill workers. Egyptian Journal of Chest Disease and Tuberculosis. 2013; 62 (4): 745-53.

17. Mamane A, Baldi I, Tessier JF, Raherison C, Bouvier G. Occupational exposure to pesticides and respiratory health. European Respiratory Review. 2015; 24 (136): 306-19. 